Saudi Journal of Medical and Pharmaceutical Sciences

Abbreviated Key Title: Saudi J Med Pharm Sci ISSN 2413-4929 (Print) |ISSN 2413-4910 (Online) Scholars Middle East Publishers, Dubai, United Arab Emirates Journal homepage: https://saudijournals.com/sjmps

\title{
Commotio Retinae after Severe Blunt Eye Trauma
}

\author{
Imane Chabbar", Louai Serghini, Zakia Hajji, Amina Berraho
}

Ophthalmology B Department, Ibn-Sina University Hospital, Rabat, Morocco

DOI: $10.36348 /$ sjmps.2020.v06i06.009

| Received: 16.06.2020 | Accepted: 23.06.2020 | Published: 30.06.2020

*Corresponding author: Imane Chabbar

\section{Abstract}

Commotio retinae or Berlin's edema is an acute traumatic maculopathy complicating blunt eye trauma. It is characterized by a transient retinal opacification affecting particularly the macular area. Its functional evolution is very variable, ranging from complete recovery to profound visual deficits with an acute and permanent visual loss. We report two cases of Commotio retinae (Berlin's edema) occurring after blunt ocular trauma of different severity and we emphasize the interest of OCT in the diagnosis, monitoring and prognostic evaluation of traumatic maculopathy.

Keywords: Commotio retinae, Berlin's edema, blunt ocular trauma, optical coherence tomography OCT.

Copyright @ 2020: This is an open-access article distributed under the terms of the Creative Commons Attribution license which permits unrestricted use, distribution, and reproduction in any medium for non-commercial use (NonCommercial, or CC-BY-NC) provided the original author and source are credited.

\section{INTRODUCTION}

Blunt eye injuries represent a real public health problem with both individual and societal repercussions $[1,2]$. All eye structures can be involved with variable severity. Berlin's edema is an acute traumatic maculopathy also called Commotio retinae. Its functional evolution can be very variable, going from ad integrum recovery to deep visual deficits with an acute and permanent visual loss. The benefit of corticotherapy, even started early, is still much debated today. We report two cases of Commotio retinae (Berlin's edema) occurring after severe blunt eye trauma and we emphasize the OCT utility in the diagnosis and follow-up of traumatic maculopathy.

\section{CASes Report}

Case 1: A 21-year-old male patient, presented with an acute loss of visual acuity in the left eye following a blunt trauma (a punch). The best corrected visual acuity was $10 / 10$ in the right eye and $1 / 10$ in the left eye. The examination of the left eye showed a normal anterior segment. The eye fundus examination revealed an abnormal discoloration of the macular area with absent foveal reflex and a normal optic disc. The examination of the right eye was normal. Macular OCT revealed an inverted foveal depression and a hyperreflectivity with uplift of retro-foveal photoreceptors (Figure 1). The diagnosis of Berlin's edema was confirmed. The patient received a bolus of Solumedrol for 3 successive days and corticosteroids eye drops with progressive degression. The evolution was marked by a resolution of Berlin's edema concomitant with an anatomical improvement; the visual acuity was also improved.

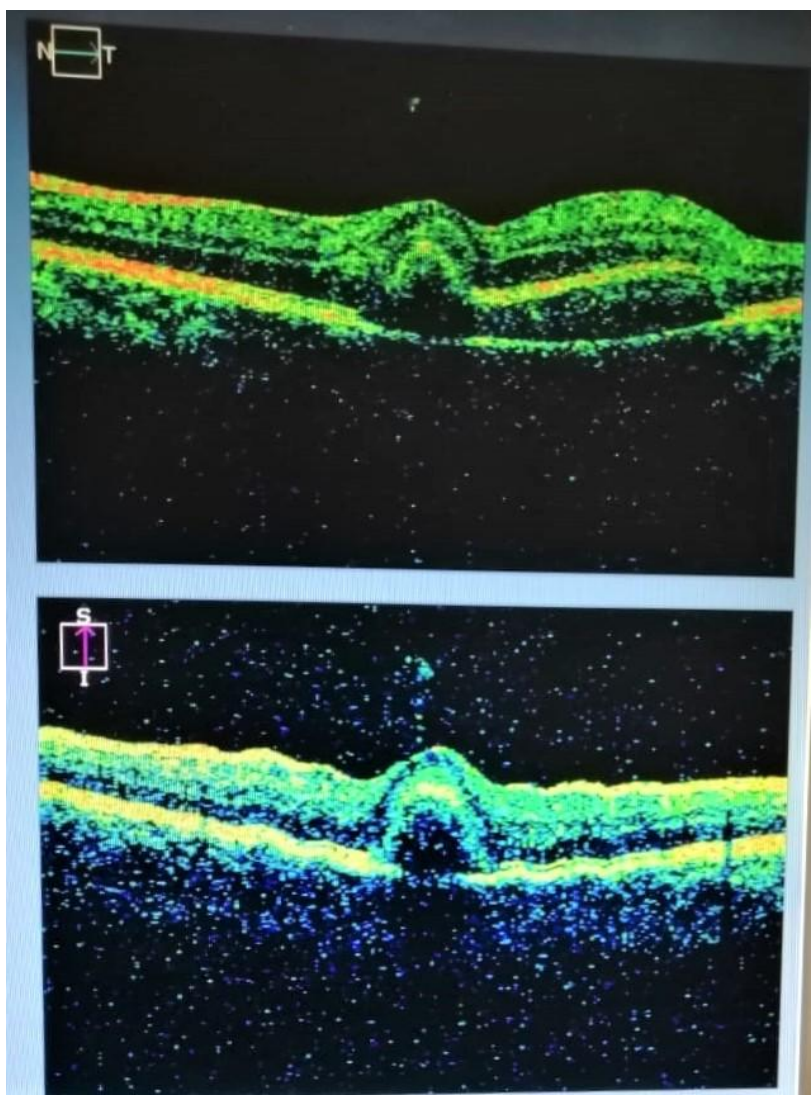

Fig-1: Macular OCT showing an inverted foveal depression and an hyperreflectivity with uplift of retro-foveal photoreceptors layer 
Case 2: A 16-year-old adolescent girl, presented with an acute loss of visual acuity in the right eye following a domestic trauma caused by a wooden bar. The best corrected visual acuity was counting fingers in the right eye and $10 / 10$ in the left eye. The examination of the right eye (Figure 2) showed diffuse subconjunctival haemorrhage, clear cornea, normal anterior chamber and areactive semi-mydriasis pupil with iris sphincter rupture at 5 and 11 o'clock. The lens was clear with normal intraocular pressure. The eye fundus examination revealed ischemic and hemorrhagic lesions of macular and peri-macular areas with a normal optic disc. The examination of the left eye was normal.

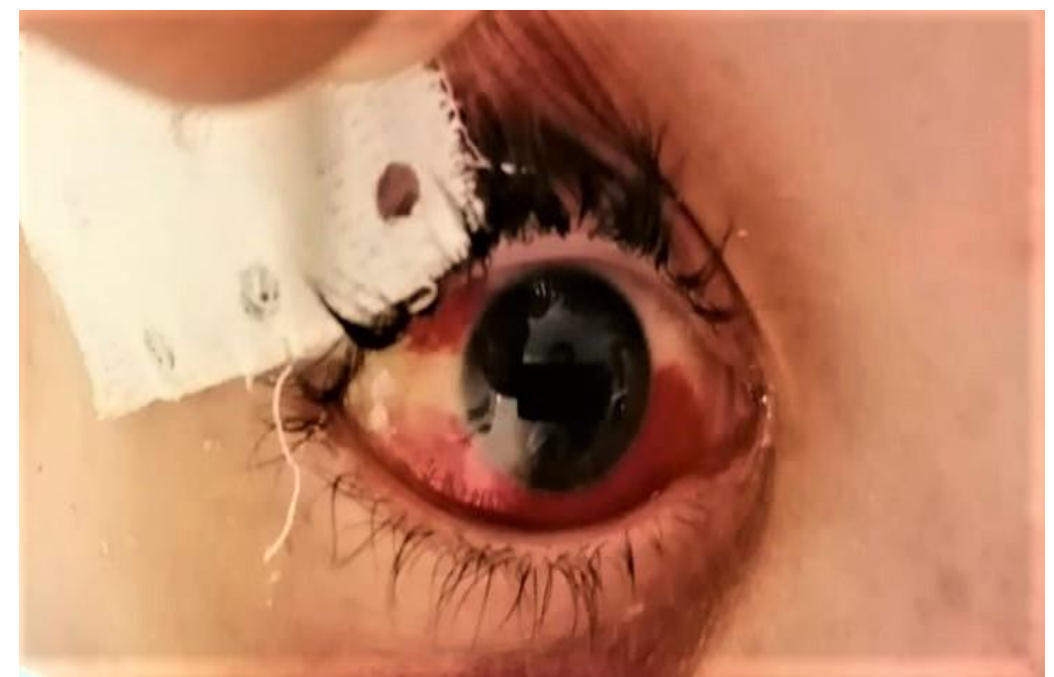

Fig-2: Photo of the right eye showing diffuse subconjunctival haemorrhage, clear cornea and areactive semi-mydriasis pupil secondary to iris sphincter rupture

OCT (Figure 3) revealed an important macular thickening with photoreceptors disorganization evoking a traumatic macular edema. The patient received a bolus of Solumedrol for 3 successive days and topical corticosteroids with progressive degression. Strict rest with abundant drinks has also been indicated. The evolution was marked by progressive resolution of Berlin's edema with a poor functional improvement.
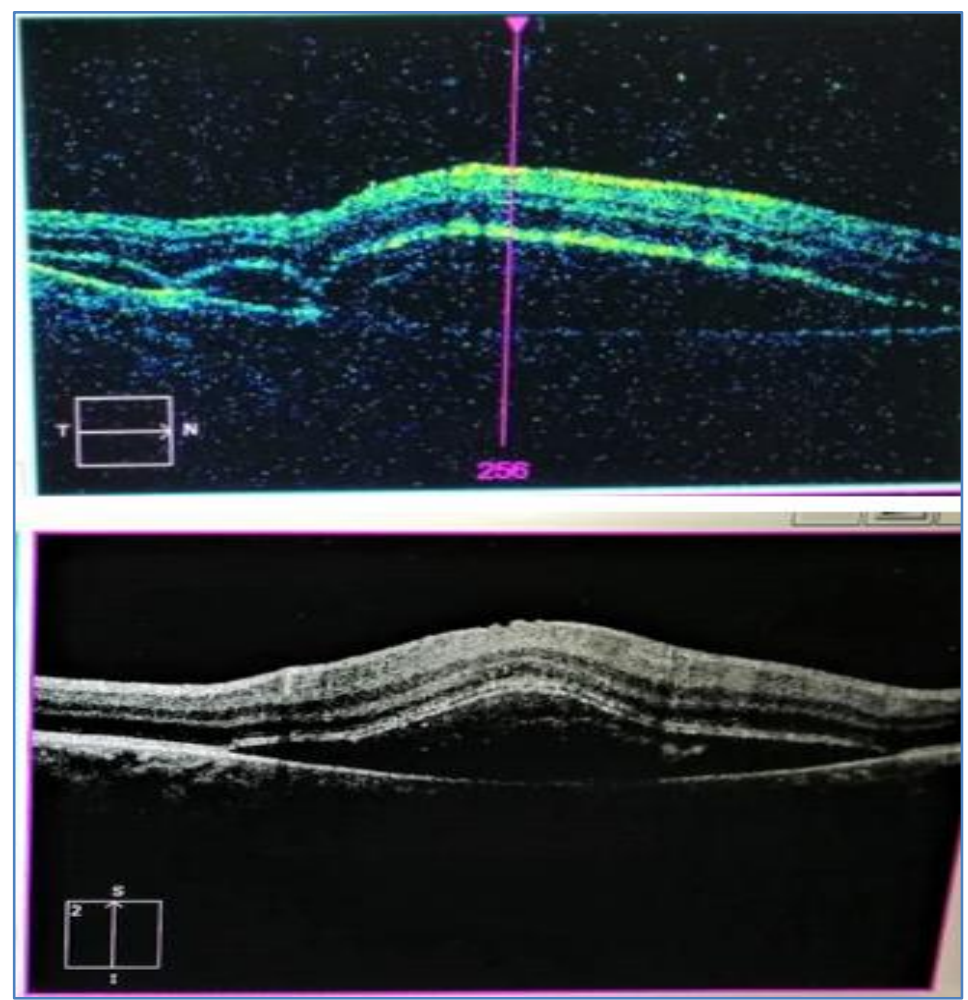

Fig-3: OCT showing an important macular thickening with photoreceptors disorganization evoking a traumatic macular edema 


\section{DISCUSSION}

Berlin's edema is an acute traumatic maculopathy also called Commotio retinae. Commotio retinae is characterized by a transient grey-white retinal opacification occurring after blunt eye trauma. The opacification may interest the peripheral retinal areas or may be limited to the macular area. Berlin's edema commonly corresponds to post traumatic macular edema. It was first described by Berlin in 1873 [3]. The pathophysiological mechanism has been studied extensively, and it is related to a blunt force transmitted to the retina due to the rapid deceleration of eye tissues. Severe ocular blunt trauma leads to photoreceptor layer disorganization and partial rupture of the blood-retinal barrier [4]. Recent studies have shown that the external retinal structures are most affected [5]. Other studies have found fragmentation of photoreceptors outer segments with epithelial damage of retinal pigments in patients with Berlin's edema [6]. Visual acuity of these patients can be variable depending on the macular involvement severity. The examination of eye fundus is essential; it should look for macular discoloration, pigmentary changes or possible retinal hemorrhages. Associated lesions should also be sought in the anterior segment as well as in the retinal periphery [7].

Macular OCT is an effective tool for the management of patients with posterior segment trauma. OCT is more adapted for the traumatized patient because it is a contactless method using infrared lighting. OCT is also very sensitive in identifying subtle anatomical changes [8]. In our two patients, the OCT showed the involvement of photoreceptors outer segments, which is correlated with the histopathology previously described [9]. In OCT, the increased reflectivity in the acute phase probably represents a disturbance of photoreceptors outer segments, which is reversible depending on the initial trauma extent [10]. Macular changes in OCT disappeared about a month after the trauma in our first patient, associated to a significant visual recovery. However, in the second patient, the trauma was more serious with poor recovery and progression to macular atrophy. Thus, in addition to its diagnostic interest, OCT can also have a prognostic utility. If the disorganization only concerns photoreceptors outer segments, functional recovery is favorable. However, if the trauma is severe, the inner segments of the photoreceptors can be damaged with the risk of cell necrosis and foveolar atrophic changes [11].

\section{CONCLUSION}

Commotio retinae or Berlin's edema is one of the serious manifestations of blunt eye trauma. A complete eye fundus examination is compulsory in all traumatized patients in order to look for any retinal complications. OCT remains an important useful tool for the diagnosis and monitoring of Berlin's edema, revealing traumatic macular changes and evaluating the visual recovery prognosis.

\section{Conflict of interest}

The authors declare that they have no conflict of interest.

\section{REFERENCES}

1. May, D. R., Kuhn, F. P., Morris, R. E., Witherspoon, C. D., Danis, R. P., Matthews, G. P., \& Mann, L. (2000). The epidemiology of serious eye injuries from the United States Eye Injury Registry. Graefe's archive for clinical and experimental ophthalmology, 238(2), 153-157.

2. OMS.(2006). Initiative mondiale pour l'élimination de la cécité évitable : plan d'action 2006-2011.

3. Berlin, R.(1873). Zur sogenannten commotio retinae. Klin Monatsbl Augenheilk, 1:42-78.

4. Hui, Y.N., Wu, Y.Q., Xiao, Q.S.(1993). Repair of outer blood-retinal barrier after severe ocular trauma in rabbits. Graefes Arch Clin Exp Ophthalmol, 231:365-9.

5. Mansour, A.M., Green, W.R., Hogge, C.(1992). Histopathology of commotio retinae. Retina, 12:24-8.

6. Liem, A.T., Keunen, J.E., van, Norren, D.(1995). Reversible cone photoreceptor injury in commotio retinae of the macula. Retina, 15:58-61.

7. Saleh, M.(2012). Contusions oculaires à globe fermé. EMC Ophtalmol. (Article 21-700-A-65).

8. Hee, M.R., Izatt, J.A., Swanson, E.A., Huang, D., Schuman, J.S., Lin, C.P.(1995). Optical coherence tomography of the human retina. Arch Ophthalmol, 113:325-332.

9. Pham, T.Q., Chua, B., Gorbatov, M., Mitchell, P.(2007). Optical coherence tomography findings of acute traumatic maculopathy following motor vehicle accident. Am J Ophthalmol, 143:348-50.

10. Oladiwura, D.(2014). Macular optical coherence tomography findings following blunt ocular trauma. Clin ophthalmol, 8: 989.

11. Boss, J.D. (2017). Functional and Morphological Evaluation of Traumatized Eyes With Berlin's Edema Affecting the Macula Using mfERG, Microperimetry, and SD-OCT. OSLI RETINA, 48(2): 114-121. 